\title{
Rapid manufacturing of FGM components by using electromagnetic compressed plasma deposition
}

\author{
Haiping Zou ${ }^{1, a}$, Mingwei Chen ${ }^{2, b}$ and Yao $\mathrm{Li}^{1, \mathrm{a}}$ \\ ${ }^{1}$ School of Electromechanical and Architectural Engineering, Jianghan University, \\ Wuhan, Hubei 430056, China \\ ${ }^{2}$ Dongfeng Peugeot Citroen Automobile Company LTD, Wuhan 430056, China \\ azhphust@126.com, ${ }^{\mathrm{b}} \mathrm{Chmwrj@163.com}$
}

Keywords: Rapid manufacturing; FGM; plasma deposition; electromagnetic

\begin{abstract}
Layered Manufacturing (LM) is emerging as a new technology in recent years that enables the fabrication of three-dimensional heterogeneous objects, Especially Functionally Graded Materials (FGM) whose composition or the microstructure is locally varied to alter the material properties. This paper presents a new fabrication method for fabricating FGM component by using electromagnetic compressed Plasma Deposition Manufacturing (PDM) process. Ni-base alloy/ $\mathrm{Al}_{2} \mathrm{O}_{3}$-ceramic FGM test component with continuous gradient transition composition were fabricated in the PDM process and the specimens' cross-sections were analyzed using optical metallography and Micro-hardness test. No defects were noticed on the cross-sections and the micro-hardness of the FGM component was increasing gradually while $\mathrm{Al}_{2} \mathrm{O}_{3}$-ceramic ingredient ratio increased. With the quantity of $\mathrm{Al}_{2} \mathrm{O}_{3}$-ceramic granule joined in the molten bath increasing, the crystal grain size thus reduced significantly.
\end{abstract}

\section{Introduction}

Functionally graded materials (FGM) are a new generation of engineering materials with continuous changes of microstructures and properties across the material [1]. The unique characteristics in structure distribution make FGM offer great promising characteristics such as low residual and thermal stresses and improved bonding strength between dissimilar materials. Generally the manufacturing processes that can fabricate FGM objects are Laser Engineered Net-Shaping (LENS) [2], Directed Light Fabrication (DLF) [3], and Electron Beam Freeform Fabrication (EBF) [4] , which are termed as rapid prototyping (RP) or layered manufacturing (LM). Electromagnetism compressed Plasma deposition manufacturing (PDM) [5], as a newly developed direct metal fabrication process, belongs to 3D welding. This technique is characterized by supplying head delivering a well-defined flow rate of material powder, which is deposited in molten pool formed by controlled plasma heating. Thereby full strength parts with the single or multifarious materials can be built up layer by layer, by melting and rapid solidifying the feed material into the desired shape. Those fabrication techniques involve deposition of material to create objects, unlike conventional methods, in which material is removed to obtain the final object [6]. The deposition of material can be explicitly controlled thereby providing unique opportunities to selectively deposit material. In other words, the material deposited can be varied continuously to yield a functionally graded material object with varying material distribution.

\section{Experimental procedure}

The functionally gradient materials (FGM) component was fabricated by using electromagnetic compress plasma deposition system that consists of plasma transferred arc and non-transfer arc generating unit and its cooling unit, magnetic field generator, a five-axis numerical control working 
table, and a set of flexible control 3-units synchronous powder feeder unit with a coaxial powder feed nozzle. A schematic diagram of the system is given in Fig. 1.

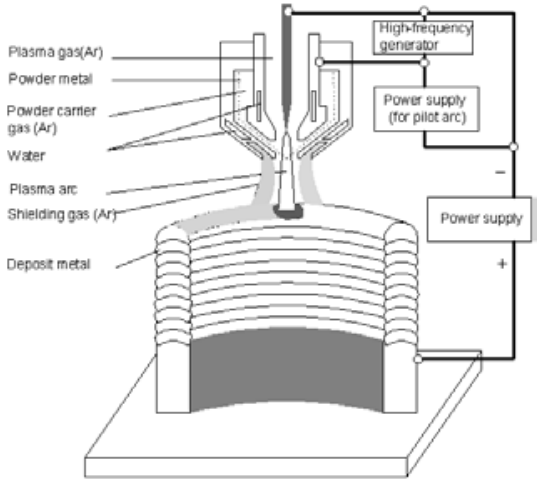

Fig. 1 Schematic diagram of electromagnetic compressed plasma deposition

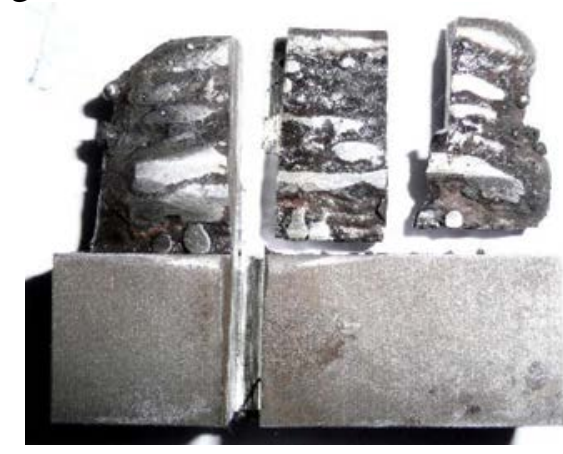

Fig. 2. The solid form of the Ni-base alloy / $\mathrm{Al}_{2} \mathrm{O}_{3}$ functionally graded material

Table.1. Plasma deposition processing parameters

\begin{tabular}{|c|c|c|c|c|c|}
\hline \multirow{2}{*}{$\begin{array}{c}\text { Transferred } \\
\text { arc current(A) }\end{array}$} & $\begin{array}{c}\text { Powder flow rate } \\
(\mathrm{g} / \mathrm{min})\end{array}$ & $\begin{array}{c}\text { Workpiece's Speed } \\
(\mathrm{mm} / \mathrm{min})\end{array}$ & Pilot gas & $\begin{array}{c}\text { Shielding } \\
\text { gas }\end{array}$ & $\begin{array}{c}\text { Carrier } \\
\text { gas }\end{array}$ \\
\hline 48 & 8 & $200-300$ & 0.15 & 0.3 & 0.36 \\
\hline
\end{tabular}

The plasma torch was mounted on a support structure of the deposition system. When fabricating the component through plasma deposition process, the plasma non-transfer arc and transferred arc beam were directed onto the substrate to create a molten pool into which the material powders were injected through the powder feed nozzle. The metal powders were melted and subsequently resolidified to form the deposition layer.

During the plasma deposition process, the feasibility, characteristic and quality of plasma deposition were influenced by many parameters such as transferred arc current, powder flow rate and the moving speed of workpiece. We adjusted the workpiece's moving speed primarily and synchronously controlled plasma arc power's match to guarantee the molten bath surface temperature's basic consistent in the entire forming process. Based on previous experiments, parameters of the optimal transferred arc current, powder flow rate and workpiece's moving speed scope used in our deposition processing were listed in Table 1.

The magnetic field used to compress the plasma arc during FGM component deposition process was generated by the magnet exciting coil which mounted on the carriage near plasma powder feed nozzle and in the position of being coaxial with the plasma torch. The magnetic field strength and the magnetic field frequency could be adjusted manually and the produced magnetic field was a longitudinal field or coaxial magnetic fields (magnetic lines of force directions were in parallel with plasma arc axial line, and formed axis-symmetrical distribution.)

A FGM component with a rectangular profile (Fig. 2.) was fabricated, with its first 4 layers (Approximately $2 \mathrm{~mm}$ from the substrate) composed of 100\% Ni-base alloy. The composition of the deposition was then changed from 0 to $57 \%$ Al2O3 over the next 28 layers. The variation in composition along the height of the solid structure was achieved by using our new developed flexible control 3-units synchronous powder feeder to deliver proper proportion of each powder according predetermined materials powder ratio of the graded structure, and then the delivered powders out of the powder feeder were well-mixed in the powder feed tube and coaxial powder feed nozzle before sending into the molten bath the powder to realize the desired ingredient gradient distribution of the component during the whole electromagnetic compress PDM fabricating process. The PDM deposition processing parameters used in the experiment were presented in Table 1 . The substrate material used for the experiment was 45 medium carbon steel sheet. The surface of the substrate was cleaned by sandblasting prior to plasma deposition. In order to eliminate any water that was trapped in the powders, the powders were dried in an oven more than $4 \mathrm{~h}$. Argon gas was also used to deliver the metal powders to prevent the melt pool from oxidizing and from oxide contamination occurring during processing. 


\section{Experimental results}

The fabricated FGM component was sliced into several cross-section specimens to measure the micro-hardness and examine the microstructure along gradient direction.

3.1 Micro-hardness of the FGM component. In our study, we used the HXD-1000 micro-hardness tester to survey micro-hardness of the deposition component. The micro-hardness measurements (load $1 / 41.961 \mathrm{~N}$ ) were carried out on the polished longitudinal cross-sections of the deposited FGM component. Fig.3. presents micro-hardness profiles along specimens' height direction (material gradient direction) cross-section. Obviously, the FGM component fabricated by electromagnetic compressed plasma deposition processing change its micro-hardness from $450 \mathrm{HV}$ at the bottom of the specimen with compositions of $100 \%$ Ni-base alloy ( $1 \mathrm{~mm}$ from the substrate) to $790 \mathrm{HV}$ at the top of the specimen with compositions of $43 \%$ Ni-base alloy and 57\%Al2O3 (15mm from the substrate).

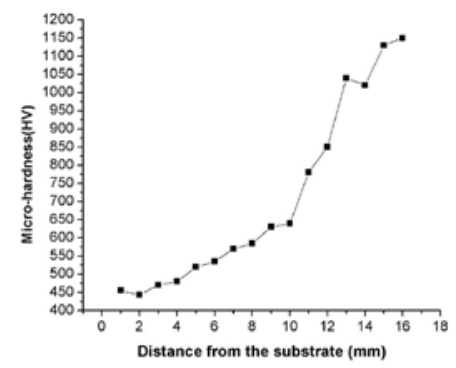

Fig.3 Longitudinal micro-hardness profiles along material gradient direction

The results revealed largely that gradual change of micro-hardness values was the result of Al2O3-ceramic ingredient gradient distribution as expected.

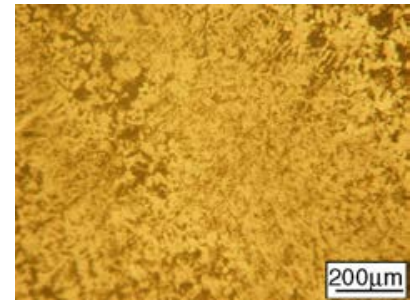

(a)

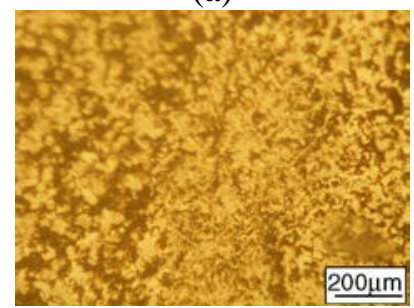

(e)

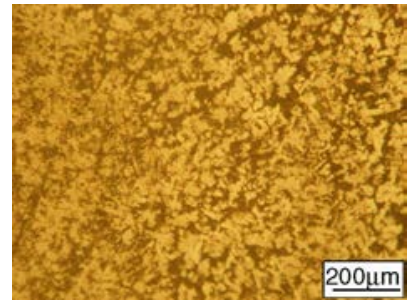

(b)

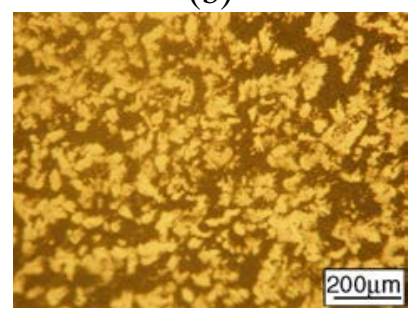

(f)

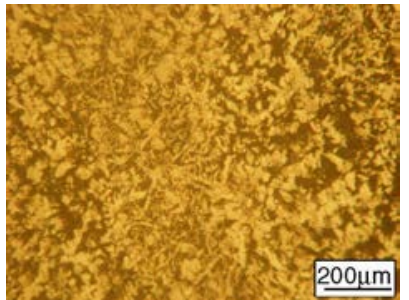

(c)

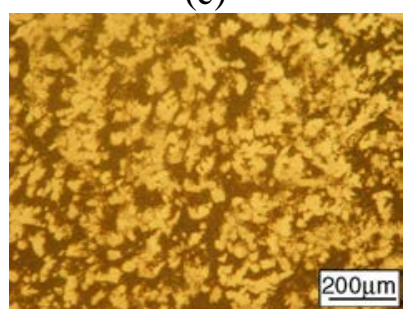

(g)

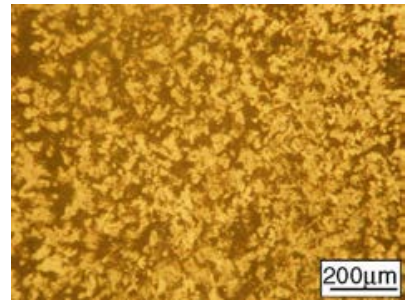

(d)

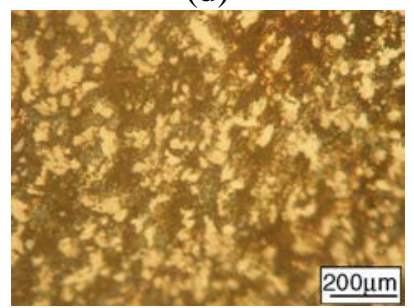

(h)

Fig. 4. The microstructure of the graded material with different compositions. (a) Ni-base alloy (1 mm from the substrate); (b) $86 \%$ Ni-base alloy $+14 \% \mathrm{Al}_{2} \mathrm{O}_{3}(3 \mathrm{~mm})$; (c) $79 \% \mathrm{Ni}$-base alloy $+21 \% \mathrm{Al}_{2} \mathrm{O}_{3}(5 \mathrm{~mm})$; (d) $72 \%$ Ni-base alloy + $28 \% \mathrm{Al}_{2} \mathrm{O}_{3}$ (7 mm); (e) 65\% Ni-base alloy + 35\% $\mathrm{Al}_{2} \mathrm{O}_{3}(9 \mathrm{~mm})$; (f) $58 \% \mathrm{Ni}$-base alloy $+42 \% \mathrm{Al}_{2} \mathrm{O}_{3}(11 \mathrm{~mm})$; (g) $50 \%$ Ni-base alloy $+50 \% \mathrm{Al}_{2} \mathrm{O}_{3}(13 \mathrm{~mm})$; (h) $43 \%$ Ni-base alloy $+57 \% \mathrm{Al}_{2} \mathrm{O}_{3}(15 \mathrm{~mm})$.

3.2 Microstructure. Fig. 4 shows the microstructures taken in cross-section parallel to the gradient direction and at various distance away from the substrate along the compositional gradient (height direction). These photos show that no defects were noticed on the whole cross-sections and the crystal grain size reduced significantly while the quantity of $\mathrm{Al}_{2} \mathrm{O}_{3}$-ceramic granule join in the molten bath increasing when formed the $\mathrm{Al}_{2} \mathrm{O}_{3}$-ceramic ingredient gradient distribution solidification layers. According to coagulation theory, nucleation rate and degree of supercooling of the metal molten bath Influence the crystal grain organization shape and size greatly. When adding $\mathrm{Al}_{2} \mathrm{O}_{3}$-ceramic powder into the molten bath formed by Ni-base alloy, the heterogeneity nucleus 
increased in the molten bath, therefore increasing nucleation rate in the solidification process of the welding tub, the liquid Ni-base alloy could be crystallized rapidly using $\mathrm{Al}_{2} \mathrm{O}_{3}$-ceramic granule as the neterogeny nucleating core. Thus changed the heat transfer way in the welding tub, caused the time of the arborescent crystal grain growing along the biggest radiation direction shortened, finally reduced the crystal grain size

\section{Conclusions}

The functionally gradient materials component of Ni-base alloy / $\mathrm{Al}_{2} \mathrm{O}_{3}$-ceramic was fabricated by using electromagnetic compress plasma deposition system. A linear compositional gradient, from $100 \% \mathrm{Ni}$-base alloy to $57 \% \mathrm{Al}_{2} \mathrm{O}_{3}$-ceramic, was achieved within a height of about $16 \mathrm{~mm}$. The micro-hardness and microstructure along the composition gradient were investigated. The results show that, within the processing parameters of the study, the micro-hardness of the deposition component increased gradually from $450 \mathrm{HV}$ at the bottom of specimen cross-section to $790 \mathrm{HV}$ at the top of specimen cross-section when the Ni-base alloy ingredient ratio changed from $100 \%$ to $43 \%$ while the $\mathrm{Al}_{2} \mathrm{O}_{3}$-ceramic ingredient ratio changed from 0 to $57 \%$. Microstructure of longitudinal section showed multi-layered construction of the component and no defects were noticed on the cross-sections. While the quantity of $\mathrm{Al}_{2} \mathrm{O}_{3}$-ceramic granule joined in the molten bath increased, the crystal grain size thus reduced significantly.

\section{Acknowledgements}

The research described in this paper was financially supported by the Wuhan Science and Technology Plan Project (201250499145-18) and Academy level project (JD023).

\section{References}

[1] Hascoet J Y, Muller P, Mognol P. Manufacturing of complex parts with continuous functionally graded materials (FGM)[C]. Austin, TX, United states: University of Texas at Austin , 2011.

[2] Xiong Y, Smugeresky J E, Ajdelsztajn L, et al. Fabrication of WC-Co cermets by laser engineered net shaping[J]. Materials Science and Engineering A. 2008, 493(1-2): 261-266.

[3] Mah R. Directed light fabrication[J]. Advanced Materials \& Processes. 1997, 151(3): 31-33.

[4] Taminger K. Electron beam freeform fabrication[J]. Advanced Materials and Processes. 2009, 167(11-12): 45.

[5] Zhang H, Xu J, Wang G. Fundamental study on plasma deposition manufacturing[J]. Surface and Coatings Technology. 2003, 171(1-3): 112-118.

[6] Niendorf T, Leuders S, Riemer A, et al. Functionally graded alloys obtained by additive manufacturing[J]. Advanced Engineering Materials. 2014, 16(7): 857-861. 